\title{
The quest for strategic Malaysian Quality National Primary School Leaders
}

\author{
Hairuddin Mohd Ali \\ International Islamic University Malaysia, Kuala Lumpur, Malaysia
}

\begin{abstract}
Purpose - The purpose of this paper is to investigate the nine-point strategic leadership characteristics of Malaysian Quality National Primary School Leaders (QNPSL) and to indicate the implications of these findings for the current educational management and leadership practices in their quest for Malaysian quality education.

Design/methodology/approach - The study selected 600 senior management team members from 150 schools to complete a seven-page questionnaire survey and eventually managed to collect back 420 completed survey questionnaires. The study employed SPSS 15.0 and a full-fledged Structural Equation Modeling (SEM) software Analysis of Moment Structures (AMOS) version 16.0 to confirm the dimensionality and the psychometric properties of the scale, as well as to test the research hypotheses. Findings - Despite what Davies and Davies suggested, the results confirm that the Malaysian QNPSL do not possess three out of nine predetermined characteristics of a strategic leader such as wisdom, strategic intervention point and strategic competence which are pertinent for efficient and effective leadership in realizing the objectives of the National Education Master Plan.

Practical implications - The findings from the study provide useful information to senior management team members of the respective schools, District and State Education Departments in improving the quality of Malaysian education.

Originality/value - As this is the first research of its kind in Malaysia, the findings to a certain extent will be able to contribute to the efforts in achieving the accessibility, equity, quality and enhancement of management goals stipulated in the National Education Master Plan (2006-2010).
\end{abstract}

Keywords Malaysian Quality National Primary School Leaders, Strategic leadership characteristics, National Education Master Plan, Primary schools, Malaysia

Paper type Research paper

\section{Introduction}

The Quality School Improvement Program (QSIP) is pertinent for schools particularly as an agent for an excellent education system. Thus, positive changes are important both at the organizational (school) and at the classroom levels. With regard to the QSIP, there has been a lot of discussions and documentation on quality school improvement characteristics and efforts (Hopkins et al., 1994; Stoll and Fink, 1996 and Harris, 1999). Several studies have clearly shown that a purposeful leadership, teacher collaboration and a central focus on learning outcomes are the factors that support positive (quality) school change (Fullan, 1993). In supporting this claim, Davies (2006), Davies and Davies (2009) and Eacott (2008) reiterated that strategic leadership is a critical component and issue that are relevant to the school leaders in the effective development of schools.

In strategizing the strategic leadership efforts, the Ministry of Education Malaysia (MOEM) formulated an Educational Development Master Plan (EDMP, 2006-2010) and recognized it as the backbone of the national plan in ensuring the achievement of
Strategic Malaysian QNPSL

Received 19 May 2010 Revised 2 November 2010 31 January 2011 Accepted 28 February 2011 
IJEM

26,1

84

Malaysia's national mission[1]. The EDMP is a continuation of the previous plan, which emphasized on accessibility, equity, quality, as well as to enhance educational management and leadership effectiveness and efficiency.

At first in 2005, a total of 350 school principals were given five days of the QSIP training (namely strategic planning in education) at the National Institute of Educational Management and Leadership (officially known as Institut Aminuddin Baki). The main objective of QSIP is to enable the educational system to develop strong, excellent and high-performing schools particularly among the National Primary Schools (NPS). Within a duration of two months, all schools involved were required to prepare and document their own five-year school strategic development plan (2006-2010). At the beginning of 2006, all 350 schools were expected to manage and implement their full-fledged strategic plans as well as to enhance their strategic leadership skills. It is believed that this would be the best time for the MOEM to monitor the Strategic Leadership Characteristics for Quality National Primary Schools Leaders (QNPSL), particularly for those who are involved with the QSIP.

\section{Understanding strategic leadership characteristics}

The researchers in the area of school effectiveness development and school improvement (Davies, 2006; Davies and Davies, 2009), consistently emphasized the importance of leadership for organizational change, development and improvement, and in determining the motivation of teachers and the quality of teaching (Harris, 2004). Harris again emphasized the need to raise the standard and to improve the outcome of schooling. This increases the pressure on the school heads to secure, sustain and demonstrate the school improvements. This inevitably further extends the changing roles of the school heads (Cranston, 2000) and those who serving in other key leadership positions (Kouzes and Posner, 2003) within the schools.

The terms used for the concepts of strategic leadership, such as "what strategic leaders do" and "characteristics that strategic leaders display" have been changed and then was elaborated further by Davies and Davies (2009). However, the author limits this study to the original nine-point model of strategic leadership (five organizational abilities and four individual characteristics of strategic leaders) that was highlighted previously (Davies, 2004; Davies and Davies, 2006, 2009). There are at least three pertinent reasons why this study employs Davies model (as depicted in Figure 1). First, the notions of strategic leadership in educational management and leadership are relatively new in Malaysia. Second, as far as strategic leadership in educational management and leadership are concerned, Davies is one of the most widely acclaimed scholars (Davies, 2004; Davies and Davies, 2006, 2009). Third, the model appears to be relevant to the present context of the Malaysian education system where the government is focusing on the outcome by referring to the key result areas (KRA).

As a critical component in the effective development of schools, strategic leadership links the strategic function with the leadership function (Davies, 2006; Davies and Davies, 2006, 2009). Therefore, possessing the strategic leadership characteristics is important as it facilitates and drives the strategic cycle of a strategically focused school (Davies, 2004; Davies and Davies, 2004, 2006, 2009; Eacott, 2008). Davies and Davies (2006) identified a nine-point model of strategic leadership that combines five organizational capabilities, and four individual characteristics of strategic school leaders as depicted in Figure 1. The five Organizational Capabilities (ORGCAPAB) as 
used by Prahalad and Hamel (1990) and Stalk et al. (1992) in this study are assumed to represent the organizational capability characteristics of the Malaysian QNPSL (in his/her capacity) to successfully undertake and implement the strategies of the school or organization. The study also assumed that the Malaysian QNPSL possess all four Individual Characteristics (INDVCHAR) that the strategic leaders should display.

Based on Davies and Davies $(2004,2006,2009)$ nine-point model of strategic leadership and Eacott (2008), the study believes that it is justifiable to hypothesize that the strategic Malaysian QNPSL possesses five organizational capability (ORGCAPAB) characteristics such as: strategic orientation; strategic translation; strategic alignment; strategic intervention; and strategic competence. On the other hand, the study also hypothesizes that the strategic Malaysian QNPSL should be able to display four individual characteristics (INDVCHAR). These are: dissatisfaction and restlessness with the present (RESTLESSNESS); absorptive capacity (ABSORPTIVE); adaptive capacity (ADAPTIVE); and wisdom (WISDOM).

\section{Research objectives}

Eacott (2008) stresses that strategic leadership is a critical issue relevant to school heads and hence it is imperative to meet the needs of the communities, which has been overlooked in the present educational leadership literature. Hence, as depicted in Figure 2, the first objective of the study is to examine the strategic leadership characteristics for the Malaysian QNPSL involved in the QSIP, based on a nine-point model of strategic leadership, which combines five organizational capabilities and four individual characteristics of the strategic leaders (Davies and Davies, 2006, 2009). This objective also includes examining how the findings of the study implicate the present practices of educational management and leadership that are relevant to the quality improvement of the Malaysian education system. The second objective is to examine which strategic leadership characteristics for the QNPSL represent the strategic leadership characteristics of the Malaysian QNPSL.

\section{Methodology}

\section{Quantitative approach}

As suggested by Soltani et al. (2006), this particular study decided to employ a survey method approach in soliciting the information about the strategic leadership characteristics of the Malaysian QNPSL. Among others, the justifications of

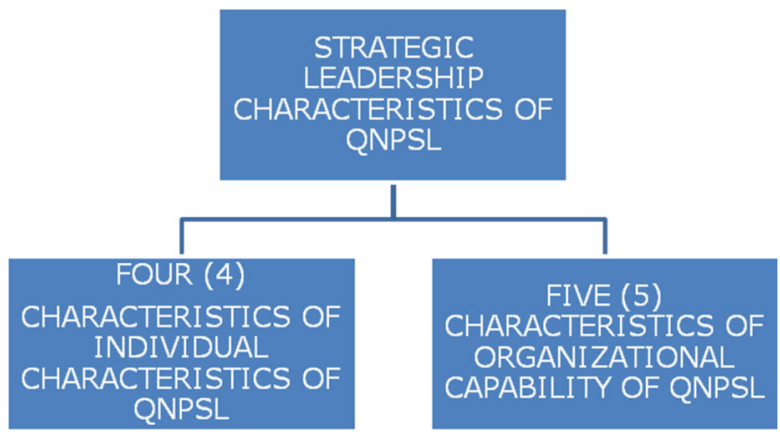

Figure 1.

The general theoretical model of the study: Strategic Leadership Characteristics of Malaysian QNPSL 
IJEM

26,1

86

Figure 2.

The hypothesized model of the study: Strategic Leadership Characteristics of Malaysian QNPSL

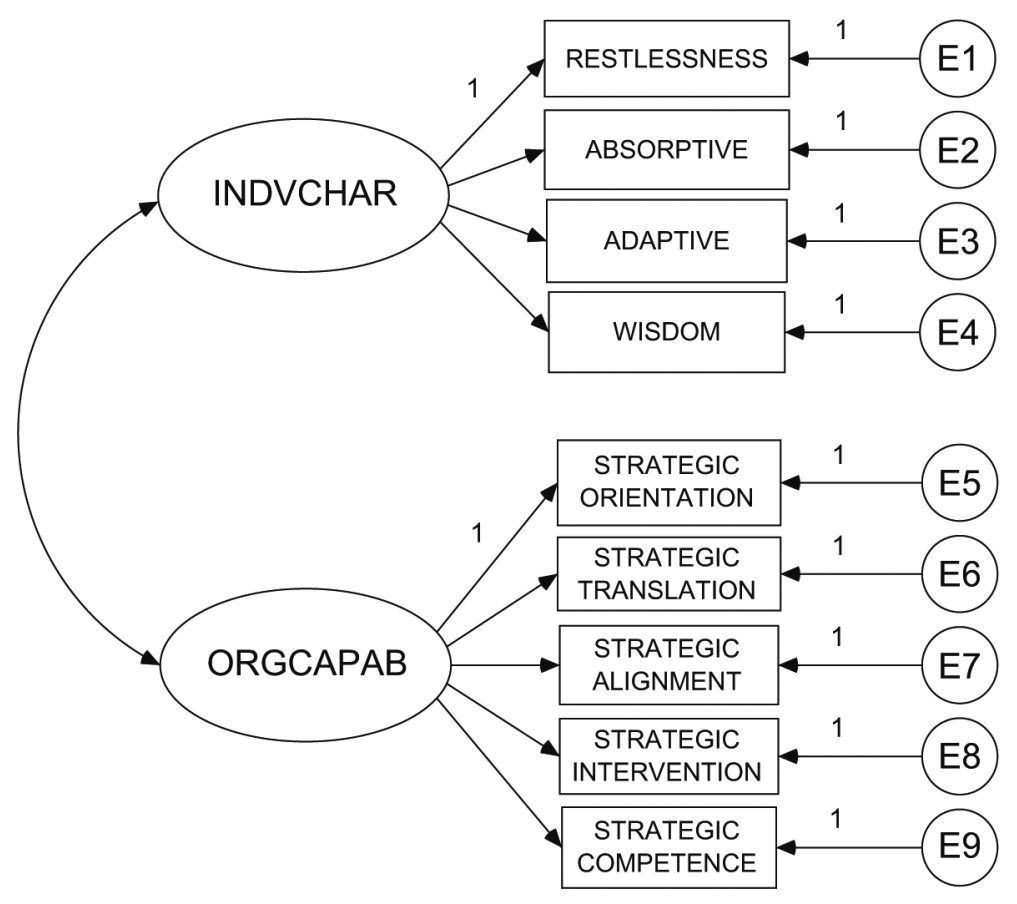

employing the quantitative approach here are, the quantitative methods ensured high levels of reliability, validity and generalizability of the gathered data (Matveev, 2002); the research was confirmatory in nature, the concept that was being measured used an ordinal scale, and the aim of the research was to classify features, to calculate, and to construct statistical models in an attempt to explain what was observed. Other justifications are, the quantitative data is more precise, able to test the hypotheses and the researcher was able to remain objectively separated from the subject matter (Smith, 1983).

\section{Sampling}

The study randomly selected 150 schools (from 350) as it provided a statistical basis for a representative sample that should be generalizable to the entire population (Fink, 1995). The researcher contacted senior management representatives from all selected schools to ensure proper completion of the returned survey questionnaire. The study targeted 600 senior management team members as sampling elements, to respond to the survey questionnaire, thus the margin of error or accuracy was \pm 4 per cent and the confidence interval 95 per cent (Ferguson, 1981; Vockell and Asher, 1995). The researcher requested that all schools involved in the study to mail the completed survey questionnaire by using the envelopes provided.

\section{Instrumentation}

The quality of questionnaire design is important for self-administered instruments (Dillman, 1983). In this case, the study used a seven-page (Malay language version) 
survey questionnaire comprising 35 items. Back-translation of the survey questionnaire verified the original translation (Brislin et al., 1973). The survey questionnaire comprised demographic questions (states, region, school's category, enrolment etc.) and 35 multiple-item questions that measure (Bearden and Teel, 1983; Churchill and Surprenant, 1982; Oliver, 1980) the strategic leadership characteristics based on Davies and Davies (2004, 2006, 2009). The items used a seven-point Likert scale $(1=$ Rarely, $4=$ Occasionally and $7=$ Almost always) and provided additional space for respondents to provide further information. The study conducted two-stage pretests (Bourque and Clark, 1992). First, two educational management and leadership experts screened the items searching for ambiguities, unclear wordings, leading (and misleading) questions and biases. Second, the study selected a group of 30 senior management team members from the sampling frame to respond to the survey questionnaire.

Several limitations cropped up when the study commenced. The most prominent limitation was the lack of response from the respondents, especially towards the end of the data collection period. There were instances where at least 30 envelopes (containing at least 90 completed questionnaires) arrived two months later (after the data collection deadline). There were also situations where three different senior management teachers provided three different demographic data although they were from the same school. However, this demographic issue was subsequently resolved and the sample size was considered adequate.

\section{Statistical analysis}

The study employed Structural Equation Modeling (SEM) and the Analysis of Moment Structures (AMOS 16.0) software (Arbuckle and Wothke, 2006), a multivariate technique combining the aspects of multiple regression and factor analysis to estimate the series of interrelated dependence relationships simultaneously (Hair et al., 2006; Loehlin, 1992). AMOS 16.0 software employed the Maximum Likelihood Estimation (MLE) in generating estimates of the full-fledged SEM and analyzed covariance matrices, the estimation procedure that satisfied the underlying statistical distribution theory, and thereby yielding estimates of desirable properties (Arbuckle and Wothke, 2006). Once the estimates of the model were established, the study applied a set of measures to evaluate its good-fit. The consistency of the model with the data was determined by eight measures, which reflected the overall model fit. Next, the study examined the magnitude and direction of individual parameter estimates to determine its reasonableness. The examination included the offending estimates such as negative error variances and theoretically inconsistent coefficients that could undermine the validity of the model. Five manifest variables namely strategic orientation (STRORIENTAT), strategic translation (STRTRANSLAT), strategic interaction (STRINTERACT), strategic alignment (STRALIGNMEN), and strategic competence (STRCOMPETE) measured the latent variable, organizational capability (ORGCAPAB). Four manifest variables namely the dissatisfaction with the present situation (RESTLESSNESS), absorptive capacity (ABSORPTIVE), adaptive capacity (ADAPTIVE) and having wisdom (WISDOM) measured the latent variable, display individual characteristics (INDVCHAR). 
IJEM

26,1

88

\section{Results}

Demographic profile of respondents

This study covered 135 schools (representing almost 90 per cent). A total of 420 (70 per cent) senior management team members responded to the survey. The confidence interval and margin of error were 95 per cent and \pm 5 per cent respectively (Ferguson, 1981; Vockell and Asher, 1995). One hundred and twenty five (125) schools represented NPS while the rest were mission schools. In terms of the school size, 115 schools were of A-grade, 16 were of B-grade and the remainder were regarded as under-enrolled schools. In terms of gender, 88 were males compared to 54 females (13 were considered missing cases). In general, the respondents seemed to be evenly distributed and almost covered the whole region. As required, the study conducted data screening to overcome problems such as sample size and missing data, multivariate normality and absence of outliers, linearity, absence of multi-colinearity and singularity (Tabachnick and Fidell, 2001). The study considered the final sample size of 406, as adequate Hair et al., 2006).

Underlying factors of strategic leadership characteristics of the Malaysian QNPSL

In general, all nine constructs possess considerably high Cronbach alphas (strategic orientation $=0.8895$, strategic intervention $=0.8911$, strategic competence $=0.9074$, strategic alignment $=0.8691$, strategic translation $=0.9420$, restlessness $=0.8658$, absorptive $=0.9040$, adaptive $=0.8238$, and wisdom $=0.9346$ ) and hence indicating high internal consistency (Sekaran, 2003 and Nunnally, 1978).

The study employed Confirmatory Factor Analysis (CFA) on the data $(N=406)$ to confirm the factors underlying the strategic leadership characteristics of the Malaysian QNPSL and hence its construct validity (convergent and discriminant). The study employed AMOS 16.0 (Arbuckle and Wothke, 2006) for maximum likelihood estimation in generating estimates of parameters in the measurement model. As shown in Figure 3, all measured variables for organizational capability or ORGCAPAB and individual characteristics or INDVCHAR are heavily loaded into their respective latent variables and hence fulfill the construct validity. The results of the CFA as depicted in Table I produced fit indices, which exceeded their respective threshold value.

The likelihood-ratio chi-square statistic $(\chi 2)$ is the most fundamental measure of overall fit (Hair et al., 2006). Hence as in Table I, the hypothesized model exhibits the likelihood-ratio chi-square $(\chi 2)$ of $(26, N=406)=181.33 ; p=0.000$. However, the model yields an unacceptable level of discrepancy between the observed data and the hypothesized model divided by the degrees of freedom $(\mathrm{CMIN} / \mathrm{df}=6.974)$. Other fit indices particularly the Adjusted Goodness of Fit Index (AGFI) and the Root Mean Square Error of Estimation (RMSEA) also did not fulfill the threshold values indicated, although the values of other fit indices, Tucker-Lewis Index (TLI), Normed Fit Index (NFI), Comparative Fit Index (CFI) and Goodness of Fit Index (GFI) are somewhat better than their respective thresholds and hence these reflect the need for the model's revision and re-evaluation.

Revised evaluation model of strategic leadership characteristics of the Malaysian QNPSL Tabachnick and Fidell (2001) suggested that there are at least two reasons for modifying a SEM model. First, to improve fit and parsimony, and second, to test the hypotheses. The re-specification of the model involved omitting certain parts of the 


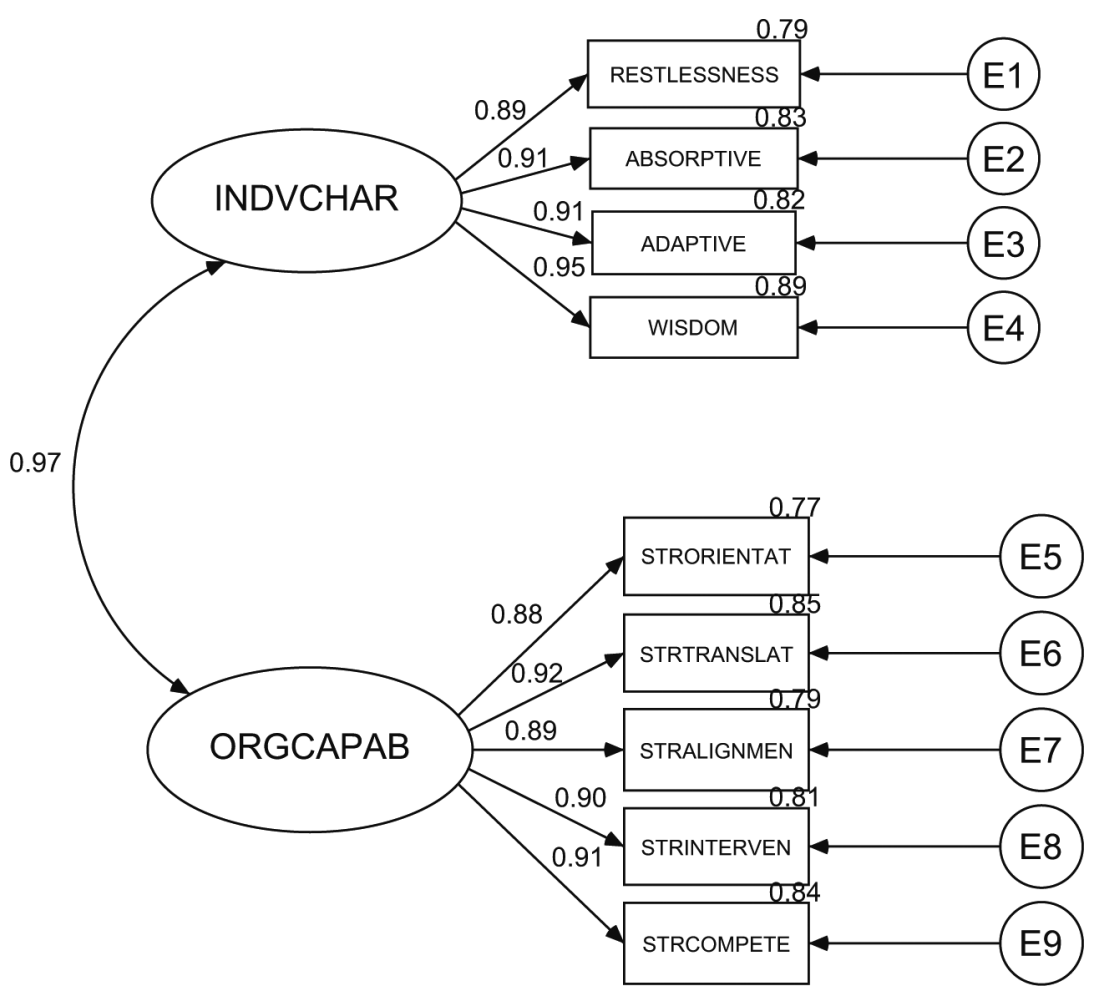

Strategic
Malaysian
QNPSL

89

model with the aim of improving the significance of the model and hence improving its good-fit. Thus, the revised model (Figure 4) is supposedly able to display better causal relationships compared to the hypothesized model (Figures 2 and 3).

As a basic model modification procedure, the study employed the Chi-square difference test (Tabachnick and Fidell, 2001). The Chi-square for the hypothesized model with 26 degrees of freedom is $\chi 2=181.33 ; p=0.000$, and the Chi-square for the revised model with 8 degrees of freedom is $\chi 2=23.34 ; p=0.000$. Therefore the Chi-square difference test (or likelihood ratio for maximum likelihood) yielded $\chi^{2}=(181.33-23.34)=157.99, \mathrm{df}=(26-8)=18, p=0.000$. This proves that the re-specification of the model significantly improved the model's fit as shown by Table I, where the level of discrepancy between the observed data and the revised model divided by the degrees of freedom yielded better fit at CMIN/df $=2.917$, compared to 6.974 for the hypothesized model. As for the absolute fit, GFI $=0.982$ and RMR $=$ 0.087 for the revised model. The RMSEA $=0.069$ that is well below the threshold value of 0.08 . All these values indicate better fit for the revised model.

In terms of the incremental fit measures, AGFI, TLI and NFI values were 0.954, 0.989 and 0.991 , respectively and hence fulfilled their threshold values. There were also no indications of insignificant values, thus proving that the revised model almost perfectly fitted the dataset. In conclusion, all three types of good-fit indices, which the study discussed previously, managed to prove that the study had successfully 


\section{IJEM \\ 26,1}

\section{0}

\begin{tabular}{|c|c|c|c|}
\hline \multirow[b]{2}{*}{ Measures } & \multicolumn{2}{|c|}{ Fit indices of the models } & \multirow[b]{2}{*}{ Threshold values } \\
\hline & Hypothesized & Revised & \\
\hline $\mathrm{CMIN} / \mathrm{df}$ & 6.974 & 2.917 & Less than 5 \\
\hline Goodness of Fit Index (GFI) & 0.906 & 0.982 & 0.90 and above \\
\hline Adjusted Goodness of Fit Index (AGFI) & 0.837 & 0.954 & 0.90 and above \\
\hline $\begin{array}{l}\text { Root Mean Square Error of Estimation } \\
\text { (RMSEA) }\end{array}$ & 0121 & 0069 & 008 and less \\
\hline Tucker-Lewis Index (TLI) & $\begin{array}{l}0.121 \\
0.955\end{array}$ & 0.989 & 0.90 and above \\
\hline Bentler-Bonett Normed Fit Index (NFI) & 0.962 & 0.991 & 0.90 and above \\
\hline Comparative Fit Index (CFI) & 0.967 & 0.994 & 0.90 and above \\
\hline Root Mean Square Residual (RMR) & 0.184 & 0.087 & $\begin{array}{l}\text { The nearer to zero the } \\
\text { better }\end{array}$ \\
\hline Number of variables in the model & 20 & 14 & \\
\hline Number of observed variables & 9 & 6 & \\
\hline Number of unobserved variables & 11 & 8 & \\
\hline Number of exogenous variables & 11 & 8 & \\
\hline Number of endogenous variables & 9 & 6 & \\
\hline Number of distinct sample moments & 45 & 21 & \\
\hline $\begin{array}{l}\text { Number of distinct parameters to be } \\
\text { estimated }\end{array}$ & 19 & 13 & \\
\hline Sample size & 406 & 406 & \\
\hline Degrees of freedom & $(45-19)=26$ & $(21-13)=8$ & \\
\hline Chi-square & $\mathrm{X}=181.33$ & $\mathrm{X}=23.339$ & \\
\hline $\mathrm{P}$ value & $p=0.000$ & $p=0.003$ & \\
\hline
\end{tabular}

\section{Table I.}

Fit indices of the hypothesized and revised model of the study developed and identified a better fit and parsimonious model of strategic leadership characteristics of the Malaysian QNPSL.

Having assessed the overall model and aspects of the measurement model, the next step was to examine the estimated coefficients for both practical and theoretical implications (Hair et al., 2006). The re-specification of the measurement model (as depicted in Figure 4) yielded two latent variables (INDVCHAR and ORGCAPAB) measured by three indicators each. Individual characteristics or INDVCHAR were measured by RESTLESSNESS (0.90), ABSORPTIVE (0.92) and ADAPTIVE (0.88), while organizational capability or ORGCAPAB were measured by strategic orientation $($ STRORIENTAT $=0.90)$, strategic translation $($ STRTRANSLAT $=0.94)$ and strategic alignment (SRTALIGNMEN $=0.89$ ).

In summary, the study had determined and confirmed the presence of only six indicators of strategic leadership characteristics of the Malaysian QNPSL that were involved in the QSIP. During the process of model modification and re-specification, the study excluded three indicators, particularly, having wisdom (WISDOM) for INDVCHAR and strategic intervention (STRINTERVEN) and strategic competence (STRCOMPETENCE) for ORGCAPAB in an attempt to confirm the presence of all nine strategic leadership characteristics of the Malaysian QNPSL that were involved in the QSIP. The correlation between these two latent variables (INDVCHAR \& ORGCAPAB) is considered high (0.94) but it is less than unity (Burgers et al., 2000) which indicates that the measured variables for INDVCHAR and ORGCAPAB remained intact and relevant. 


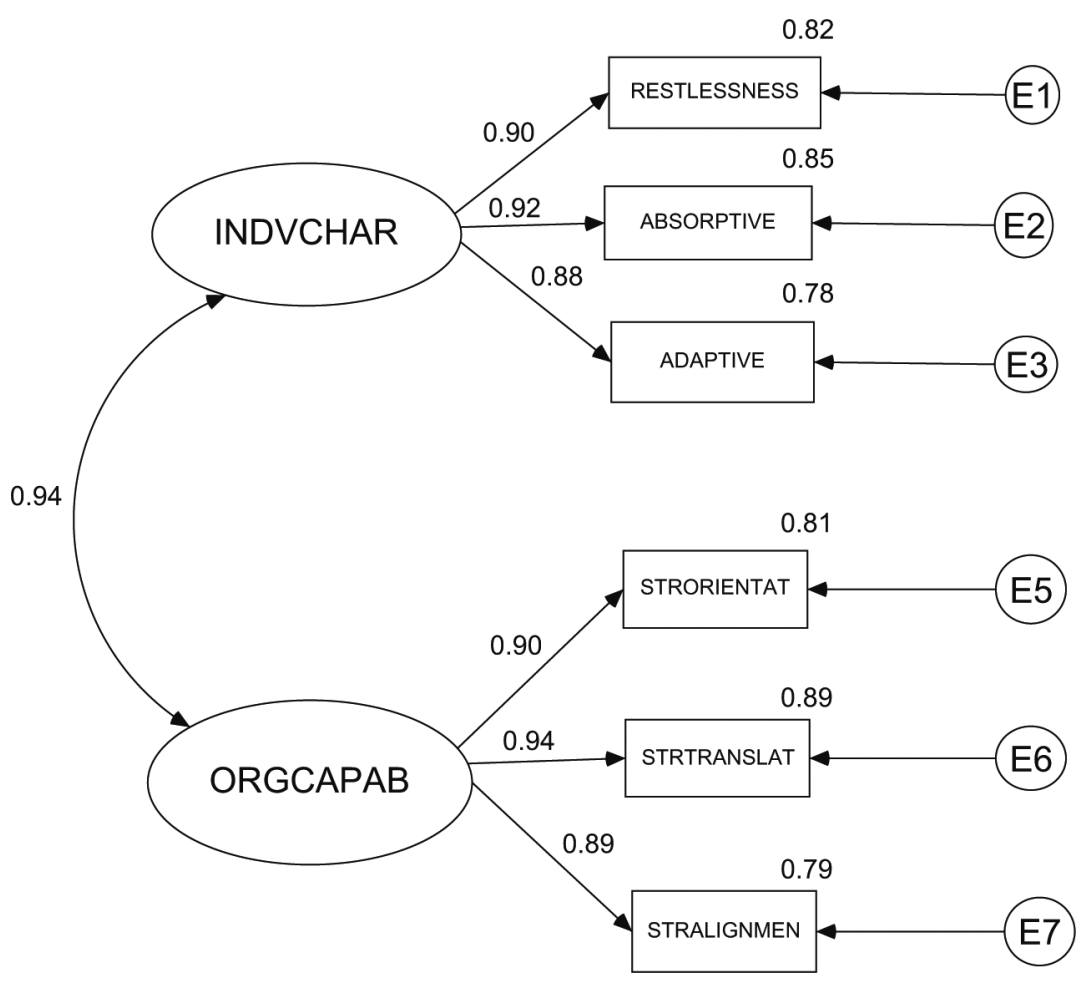

Figure 4.

Generated revised model of the study (Strategic Leadership Characteristics of Malaysian QNPSL)

Testing of the hypotheses

SEM is a statistical methodology used for hypothesis and model testing (i.e. confirmatory) of the multivariate analysis (Byrne, 1994; Tabachnick and Fidell, 2001). The study used the results as exhibited in Table I and the generated revised model, as in Figure 4, to examine if the revised model supported the research hypotheses of the study at 0.05 significance level.

As exhibited in Table II, the result confirmed that, in terms of organizational capability, the Malaysian QNPSL possessed only three out of five strategic characteristics, namely: strategic orientation (STORIENTAT)], strategic translation (STRTRANSLAT) and strategic alignment (STRALIGNMEN). However, for individual characteristics, the Malaysian QNPSL possessed three out of four characteristics, namely: RESTLESSNESS, ABSORPTIVE and ADAPTIVE.

In contrast, the study was unable to confirm the presence of the two remaining organizational capability characteristics among the Malaysian QNPSL, particularly "determine effective strategic intervention points" (STRINTERVEN) and "develop strategic competencies" (STRCOMPETE). The study was also unable to confirm the presence of the WISDOM characteristic as one of the strategic leadership features of the Malaysian QNPSL. Table II below exhibits the summary of the hypotheses that were tested in this study. 


\begin{tabular}{|c|c|c|c|c|}
\hline $\begin{array}{l}\text { IJEM } \\
26,1\end{array}$ & Hypotheses & Strategic Malaysian QNPSL & Identification & $\begin{array}{l}\text { Supported/ } \\
\text { unsupported }\end{array}$ \\
\hline \multirow[b]{2}{*}{92} & $\begin{array}{l}\text { Organization } \\
\text { H1 }\end{array}$ & Strategically oriented & $\begin{array}{l}\text { Strategic orientation/ } \\
\text { STRORIENTAT }\end{array}$ & Supported \\
\hline & $H 2$ & Translate strategy into action & $\begin{array}{l}\text { Strategic translation/ } \\
\text { STRTRANSLAT }\end{array}$ & Supported \\
\hline \multirow{9}{*}{$\begin{array}{l}\text { Table II. } \\
\text { Summary of hypotheses } \\
\text { tested }\end{array}$} & $H 3$ & Align people and organization & $\begin{array}{l}\text { Strategic alignment/ } \\
\text { STRALIGNMEN }\end{array}$ & Supported \\
\hline & $H 4$ & $\begin{array}{l}\text { Determine strategic intervention } \\
\text { points }\end{array}$ & $\begin{array}{l}\text { Strategic intervention/ } \\
\text { STRINTERVEN }\end{array}$ & Unsupported \\
\hline & H5 & Develop strategic competencies & $\begin{array}{l}\text { Strategic competence/ } \\
\text { STRCOMPETE }\end{array}$ & Unsupported \\
\hline & \multicolumn{2}{|c|}{ Individual characteristics $^{\mathrm{b}}$} & & \\
\hline & $H 6$ & $\begin{array}{l}\text { Dissatisfaction and restlessness with } \\
\text { the present }\end{array}$ & RESTLESSNESS & Supported \\
\hline & $H 7$ & Absorptive capacity & ABSORPTIVE & Supported \\
\hline & H8 & Adaptive capacity & ADAPTIVE & Supported \\
\hline & H9 & Having wisdom & WISDOM & Unsupported \\
\hline & \multicolumn{3}{|c|}{ Notes: ${ }^{\mathrm{a}} n=5{ }^{\mathrm{b}} n=4$} & \\
\hline
\end{tabular}

\section{Discussion and managerial implications}

The study identified that all senior management staff/teachers (also known as the deputies) such as senior assistants for administration, student affairs, extra co-curricular activities and the afternoon session supervisor (who were the respondents for the study) were the most powerful group members in their schools. The study assumed that to a certain extent, they managed to influence the school leadership. As the deputies, they were always shadowing their school leaders and hence became the most appropriate subordinates to evaluate their respective leaders (Kouzes and Posner, 2003).

Organizational capability of the Malaysian QNPSL

In case of the Malaysian QNPSL for the QSIP, the study supported that they possessed only three organizational capabilities of strategic leadership characteristics as discussed previously. Davies (2004), Davies and Davies (2004, 2006, 2009) described the characteristic as "being strategically oriented" (STRATEGIC ORIENTATION) and it was obvious that the Malaysian QNPSL were strategically oriented as required by the stakeholders (particularly the MOEM), and hence conformed to the Standards of Competency for Malaysian School Principals (2006). Equipped with this particular characteristic, the Malaysian QNPSL also fulfilled the Quality Standards for Malaysian Education (2004). However, unlike the UK (Preedy et al., 2003), strategic planning and strategic leadership concepts were introduced only quite recently in the Malaysian education system in conjunction with the inception of the EDMP (2006-2010). Here, the achievement of the key result areas (KRA) and key performance indicators (KPI) are considered mandatory. Hence, the achievements of the strategic implementation of the EDMP will be of a great importance from 2010 onwards. 
Davies (2004), Davies and Davies (2004, 2006, 2009) described "ability to translate strategy into action" (STRATEGIC TRANSLATION) as one of the organizational capability characteristics of strategic leadership, while Kaplan and Norton (2004) suggested that strategic translation characteristic is essential for strategy management implementation success. Hence, the possession of this particular capability would enable the stakeholders to differentiate between the true strategic implementers (such as the Malaysian QNPSL) from mere lip-servers and mediocre school leaders. The strategic implementers are those who are able to turnaround the schools as compared to the pseudo-leaders who are just holding on to their status-quo and surviving. As the ability to translate strategy into action is one of the main components of strategic management implementation (Kaplan and Norton, 2004) and the strategic planning for public organizations (Bryson, 2003), the study successfully identified it to be one of the leadership skills needed by the Malaysian QNPSL. Hence, this also fulfills both the Standards of Competency for Malaysian School Principals (2006) and the Quality Standards for Malaysian Education (2004).

The study also supports that "aligning people and organization" (STRATEGIC ALIGNMENT) is one of the organizational capability characteristics of strategic leadership of the Malaysian QNPSL (Davies, 2004; Davies and Davies, 2004, 2006, 2009). The Malaysian QNPSL deputies that evaluated his or her school leaders confirmed this from their perception; "the leaders possessed the required leadership powers that enabled them to align his or her staff with the organization”. Such powers are legitimate powers, coercive powers, reward powers, expert powers and referent powers (Maxwell, 2001). By possessing these characteristics, it enabled the leaders to change the mindset as well as the behavior of their subordinates through strategic conversation, strategic participation and strategic motivation and hence building personal and organizational capability (Davies and Davies, 2009; Prahalad and Hamel, 1990; Stalk et al., 1992).

The "ability to develop strategic capabilities" (STRATEGIC COMPETENCE) is one of the organizational capability characteristics of strategic leadership (Davies, 2004; Davies and Davies, 2004, 2006, 2009). However, the study did not support the presence of strategic competence characteristic (STRCOMPETE) among the Malaysian QNPSL. As instructional leaders, the "ability to identify strategies to improve student learning", the "avoidance of scapegoat culture", the "ability to interpret data for student achievement", and "team problem solving" are considered mandatory leadership characteristics. However, in case of the Malaysian QNPSL, the ability to identify the strategies to improve student learning and the ability to interpret the data for student achievement are important, particularly for the high performing schools, as required by the Standards of Competency for Malaysian School Principals (2006) and the Quality Standards for Malaysian Education (2004). In addition, by practicing the team problem solving and the absence of a "scapegoat culture", will ensure that the Malaysian QNPSL possess the necessary skills to create and manage the culture (Hargreaves, 2003) successfully. Unfortunately, with the absence of strategic competence characteristic among the Malaysian QNPSL, it will definitely become a huge obstacle in steering the high performance schools, as they lack of creativity in problem solving skills and teamwork, which are necessary for strategic capabilities (Prahalad and Hamel, 1990; Stalk et al., 1992; Davies and Davies, 2006, 2009).
Strategic Malaysian QNPSL

93 
IJEM

26,1

94
Another organizational capability characteristic is the "effective strategic intervention points" or STRATEGIC INTERVENTION (Davies, 2004; Davies and Davies, 2004, 2006, 2009). However, the study confirms that this particular characteristic is non-dominant in the Malaysian QNPSL case, which consequently would negatively affect the schools concerned as it shows the inability of the Malaysian QNPSL to control and monitor the strategic implementation of their school strategic plan. Further, as reiterated by Davies and Davies $(2006,2009)$, the leaders will face huge disadvantages as they would not be able to do the right things at the right time, to know what to do, how and when to make capacity available for improved practice in the future. However, this particular study is unable to confirm the specific derailment of the strategic process as the study is only focused on the presence (or absence) of the strategic leadership characteristics among the Malaysian QNPSL for QSIP.

In summary, the study shows that there are only three dominant characteristics of organizational capabilities or ORGCAPAB, namely, "strategic orientation, strategic translation and strategic alignment" among the Malaysian QNPSL concerned. The characteristics such as the "strategic intervention point and the strategic competence", which are considered extremely important, are non-dominant. A further in-depth study of how far these imbalances of characteristics would affect the strategic leadership performance of the Malaysian QNPSL is urgently needed for future knowledge enrichment as well as for the betterment of the Malaysian educational system.

\section{Individual characteristics of the Malaysian QNPSL}

The study proves and confirms that the Malaysian QNPSL for the QSIP possessed only three individual characteristics of strategic leadership, namely, "a dissatisfaction or restlessness with the present" (RESTLESSNESS), "absorptive capacity" (ABSORPTIVE) and "adaptive capacity" (ADAPTIVE).

Davies and Davies $(2004,2006,2009)$ classified the individual characteristics of "dissatisfaction or restlessness with the present", that the Malaysian QNPSL possessed as extremely important since it shows the ability to challenge the ideas and processes in seeking better ideas for the benefit of the communities. This characteristic is also pertinent for the Malaysian QNPSL, as Barker (1992) reiterated that "vision without action is merely a dream and while vision with action can change the world". From this point, the stakeholders can expect the best from the Malaysian QNPSL concerned and thus enable them to fulfill the "third goal of the Malaysian EDMP (2006-2010)".

The study also supports the presence of the "ability to absorb the available information" or shortly ABSORPTIVE characteristic, which is obviously important for the student performance achievement (Davies, 2004; Davies and Davies, 2004, 2006, 2009). By having this capability (Prahalad and Hamel, 1990; Stalk et al., 1992), the school leaders are able to conduct the strategic analyses (including the environmental or situational aspects) prior to the preparation of the school strategic development planning (Bryson, 2003; Preedy et al., 2003). Thus, the Malaysian QNPSL should focus on the ongoing learning, through interaction with environmental information, absorbing and assimilating new information, learning and applying them effectively as they are considered equally important in the process of developing the individual and the organization's capacities to interpret external events and to identify the key trends that needed to be responded to (Senge, 1990). 
The Malaysian QNPSL deputies also perceived the presence of the "adaptive capacity" or ADAPTIVE characteristic among their superiors. In accordance with the strategic planning literature (Bryson, 2003), the adaptive capacity characteristic of a leader is obviously important because the possession of this characteristic will enable the Malaysian QNPSL to adopt and adapt the generated strategies (Eacott, 2008) following the changes in the environment. This ability is vital to a strategic leader of the Malaysian QNPSL, as the effective strategies generated would ensure the achievement of their organizational goals. The creativity and the authentic experiences of the strategic leaders would also influence and affect their adaptive capacity.

Despite possessing the three dominant individual characteristics, as mentioned previously, the study also proves that the Malaysian QNPSL do not possess the "leadership wisdom" or WISDOM which is considered as the core element of leadership (Rowley, 2006) and hence a very important characteristic for a strategic leader (Davies, 2004, Davies and Davies, 2006, 2009). The literature (other than what Davies and Davies, 2006, 2009 has defined) describes leadership's wisdom comprised intellectual aspect, wise judgment; belief in the team's ability and excellent application of knowledge for organizational success (Bierly et al., 2000; Small, 2004; Rowley, 2006a, b; Bennet and Bennet, 2008). With the absence of WISDOM, what can the stakeholders expect from the Malaysian QNPSL? What would be the fate of an organization if a "non-wisdom" leader leads it? (Small, 2004). Bierly et al. (2000) suggested three important drivers for organizational development and leadership wisdom namely experience, a passion to learn and possessing a high spirituality. This involves at least a change of policy particularly in the aspect of leadership and management development programs for the Malaysian QNPSL in future (Small, 2004). The challenges will be greater if the people wisdom, contextual wisdom and procedural wisdom (Davies and Davies, 2006, 2009) are taken into account and hence will affect the success of fulfilling the third goal of the Malaysian EDMP (2006-2010).

\section{Future research and conclusion}

Generally, the study provides us with some insights on the status of the strategic leadership characteristics among the Malaysian QNPSL for the QSIP. The study also confirms that all Malaysian QNPSL generally possess six (out of nine) dominant strategic leadership characteristics as suggested by Davies (2004) and Davies and Davies (2004, 2006, 2009). Despite that, there is also a setback as the Malaysian QNPSL in this particular study was also found to be lacking in three important strategic leadership characteristics namely strategic "intervention point", "strategic competence" and "leadership wisdom" which are obviously very important for the school success. The implications could be very serious as it might hinder the achievement of the MOEM's Master Plan's (2006-2010) strategic goals. The findings from this study will obviously enhance the nation's indigenous knowledge in the area of strategic leadership characteristics for educational leaders that will ultimately ensure the quality of the Malaysian education system. For a wider perspective of research findings, it is suggested that a full-scale study using larger samples be conducted in future so that the findings will eventually be more applicable to the Malaysian educational setting. It is also suggested that future research should take into account of the latest strategic leadership thoughts and concepts as developed by Davies and Davies (2006, 2009) and Eacott (2008).

\section{Strategic Malaysian QNPSL}


IJEM

26,1

96
Note

1. It is part of Malaysia's Vision 2020.

\section{References}

Arbuckle, J.L. and Wothke, W. (2006), Amos 4.0 User's Guide, SmallWaters Corporation, Chicago, IL.

Barker, J.A. (1992), Future Edge: Discovering the New Paradigms of Success, William Morrow \& Company, New York, NY.

Bearden, W.O. and Teel, J.E. (1983), "Selected determinants of consumer satisfaction and complaints reports", Journal of Marketing Reports, Vol. 20, February, pp. 21-8.

Bennet, A. and Bennet, D. (2008), "Moving from knowledge to wisdom, from ordinary consciousness to extraordinary consciousness", VINE: The Journal of Information and Knowledge Management Systems, Vol. 38 No. 1, pp. 7-15.

Bierly, P.E. III, Kessler, E.H. and Christensen, E.W. (2000), "Organizational learning, knowledge and wisdom”, Journal of Organizational Change Management, Vol. 13 No. 6, pp. 595-618.

Bourque, L.B. and Clark, V.A. (1992), Processing Data: The Survey Example, Sage Publications, Newbury Park, CA.

Brislin, R., Loner, W. and Thorndike, R. (1973), Cross-cultural Research Methods, Wiley \& Sons, New York, NY.

Bryson, J.M. (2003), Strategic Planning for Public and Non-profit Organization, Jossey-Bass, San Francisco, CA.

Burgers, A., de Ruyter, K., Keen, C. and Streukens, S. (2000), "Customer expectation dimensions of voice-to-voice service encounters: a scale development study", International Journal of Service Industry Management, Vol. 11 No. 2, pp. 142-61.

Byrne, B.M. (1994), Structural Equation Modeling with EQS and EQS/Windows: Basic Concept, Applications and Programming, Sage Publications, London.

Churchill, G.A. Jr and Surprenant, C. (1982), “An investigation into the determinants of customer satisfaction”, Journal of Marketing Research, Vol. 19, pp. 491-504.

Cranston, N. (2000), "The impact of school based management on primary school principals: an Australian perspective", Journal of School Leadership, Vol. 10 No. 3, pp. 214-32.

Davies, B. (2004), "Developing the strategically focused school", School Leadership \& Management, Vol. 24 No. 1, pp. 11-27.

Davies, B. (2006), Leading the Strategically Focused School: Success and Sustainability, Sage Publications, Thousand Oaks, CA.

Davies, B. and Davies, B.J. (2009), "Strategic leadership", in Davies, B. (Ed.), The Essentials of School Leadership, 2nd ed., Sage Publications, Thousand Oaks, CA, pp. 13-35.

Davies, B.J. and Davies, B. (2004), "Strategic leadership", School Leadership \& Management, Vol. 24 No. 1, pp. 29-38.

Davies, B.J. and Davies, B. (2006), "Developing a model for strategic leadership in schools", Educational Management Administration \& Leadership, BELMAS, Vol. 34 No. 1, pp. 121-39.

Dillman, D. (1983), "Mail and other self-administered questionnaires", in Rossi, P., Wright, J.D. and Anderson, A.B. (Eds), Handbook of Survey Research, Academic Press, New York, NY.

Eacott, S. (2008), "Strategy in educational leadership: in search of unity", Journal of Educational Administration, Vol. 46 No. 3, pp. 353-75. 
Ferguson, G.A. (1981), Statistical Analysis in PhD Education, 5th ed., McGraw Hill, New York, NY.

Fink, A. (1995), The Survey Handbook, Sage Publications, London.

Fullan, M. (1993), Change Forces: Probing the Depths of Educational Reform, Falmer Press, London.

Harris, A. (1999), Teaching and Learning in the Effective School, Arena Press, London.

Harris, A. (2004), "School leadership and school improvement: a simple and complex relationship", School Leadership \& Management, Vol. 24 No. 1, (Editorial).

Hair, J.F., Black, W.C., Babin, B.J., Anderson, R.E. and Tatham, R.L. (2006), Multivariate Data Analysis, Prentice Hall International, Englewood Cliffs, NJ.

Hargreaves, D. (2003), "Helping practitioners explore their school's culture", in Preedy, M., Glatter, R. and Wise, C. (Eds), Strategic Leadership and Educational Improvement, Paul Chapman Publishing, London.

Hopkins, D., Ainscow, M. and West, M. (1994), School Improvement in an Era of Change, Cassell, London.

Kaplan, R.E. and Norton, D.P. (2004), Strategy Maps: Converting Intangible Assets into Tangible Outcomes, Harvard Business School Press, New York, NY.

Kouzes, J.M. and Posner, B.Z. (2003), Academic Administrators Guide to Exemplary Leadership, John Wiley \& Sons, San Francisco, CA.

Loehlin, J.C. (1992), Latent Variable Models: An Introduction to Factor, Path, and Structural Analysis, Lawrence Erlbaum Associates, Hillsdale, NJ.

Matveev, A.V. (2002), "The advantages of employing quantitative and qualitative methods in intercultural research: practical implications from the study of the perceptions of intercultural communication competence by American and Russian managers", Theory of Communication and Applied Communication, Vol. 1, pp. 59-67.

Maxwell, J.C. (2001), The Power of Leadership, Honor Books, Colorado Springs, CO.

Nunnally, J.C. (1978), Psychometric Theory, 2nd ed., McGraw-Hill, New York, NY.

Oliver, R.L. (1980), "A cognitive model of the antecedents and consequences of satisfaction decisions", Journal of Marketing Research, Vol. 17, September, pp. 460-9.

Prahalad, C.K. and Hamel, G. (1990), "The core competence of the corporation”, Harvard Business Review, Vol. 68 No. 3, pp. 79-87.

Preedy, M., Glatter, R. and Wise, C. (2003), "Strategic leadership challenges", in Preedy, M., Glatter, R. and Wise, C. (Eds), Strategic Leadership and Educational Improvement, Paul Chapman Publishing, London.

Quality Standards for Malaysian Education (2004), Ministry of Education Malaysia, Kuala Lumpur, Malaysia.

Rowley, J. (2006a), "Where is the wisdom that we have lost in knowledge?", Journal of Documentation, Vol. 62 No. 2, pp. 251-70.

Rowley, J. (2006b), “What do we need to know about wisdom?”, Management Decisions, Vol. 44 No. 9, pp. 1246-57.

Sekaran, U. (2003), Research Methods for Business: A Skill Building Approach, 3rd ed., John Wiley \& Sons, New York, NY.

Senge, P. (1990), The Fifth Discipline, Doubleday, New York, NY.

Small, M.W. (2004), "Wisdom and now managerial wisdom: do they have a place in management development program?", Journal of Management Development, Vol. 23 No. 8, pp. 751-64. 
IJEM

26,1

98
Smith, J.K. (1983), "Quantitative versus qualitative research: an attempt to clarify the issue", Educational Researcher, Vol. 12 No. 3, pp. 6-13.

Soltani, E., van der Meer, R., Williams, T.M. and Lai, P. (2006), “The compatibility of performance appraisal systems with TQM principles - evidence from current practice", International Journal of Operations \& Production Management, Vol. 26 No. 1, pp. 92-112.

Stalk, G., Evans, P. and Shulman, L. (1992), "Competing on capabilities: the new rules of corporate strategy", Harvard Business Review, pp. 57-69.

Standards of Competency for Malaysian School Principals (2006), Ministry of Education Malaysia, Kuala Lumpur.

Stoll, L. and Fink, D. (1996), Changing our Schools: Linking School Effectiveness and School Improvement, Open University Press, Buckingham.

Tabachnick, B.G. and Fidell, L.S. (2001), Using Multivariate Statistics, 3rd ed., Harper Collins Publishers, New York, NY.

Vockell, E.L. and Asher, J.W. (1995), Educational Research, 2nd ed., Prentice Hall, Upper Saddle River, NJ.

\section{Further reading}

Davies, B. and Ellison, L. (2003), The New Strategic Direction and Development of the School, 2nd ed., Routledge Falmer, New York, NY.

Hopkins, D., Ainscow, M. and West, M. (1996), Unraveling the Complexities of School Improvement: a case study of the Improving the Quality of Education for All (IQEA) Project. Open University Course E838 reader, Organisational Effectiveness and Improvement in Education.

\section{Corresponding author}

Hairuddin Mohd Ali can be contacted at: hairuddin@iiu.edu.my; hairuddin@iab.edu.my 